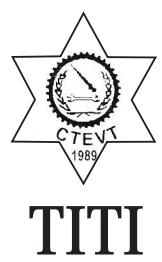

DOI: http://dx.doi.org/10.3126/jtd.v2i0.15438

ISSN: 2392-4578(Online)

\title{
Reflecting Rapid Market Appraisal: A Practical Tool for Training Needs Analysis
}

\author{
Rajendra Bahadur Shrestha \\ Capacity Building Specialist \\ Enhanced Skills for Sustainable and Rewarding Employment \\ Helvetas Swiss Intercooperation, Nepal \\ Email for correspondence: rbshres@yahoo.com or rajendra.shrestha@ helvetas.org.np
}

\begin{abstract}
In my understanding, Rapid Market Appraisal (RMA) is a comprehensive study of an employment status in the specific occupational area at the particular local level. At the cross road of my job career, I came to know that the development of this process grew out of a frustration with lengthy, costly and intensive formal market survey. I argue that this process provides a quick, flexible and effective way of collecting, processing, and analyzing information and data about labour markets. It explores information about the vocational-technical training institutions working effectively in the respective field. It also supplies detailed information like occupational opportunities, training needs, individual needs, and future prospective in the work of world at local level. Based on my practical experiences, I claim it as one of the effective tools for assessing the training needs for training design for the under-developing countries.
\end{abstract}

Key words: : Job market, training need analysis, curriculum development, training design, and technical training providers

\section{Introduction}

Assessing the real needs of business, industry, or community is one of the most important tasks for any technical training organizations. The trainings are only successful if the needs assessors have managed to identify the real demand on the job market. The training programmes, which focus on the needs of users, will be more successful (International Labor Organization [ILO], 1999).
Thus, conducting some form of a needs assessment is usually the first step when designing a training course. The success of the training depends on the success of training needs assessment. Timely revised curriculum according to the demand of the job market attracts both trainees and employers towards vocational training programmes (ILO, 1999). According to Brooke Broadbent and Lise Froidevaux (2008), training needs analysis is a process of 
gathering and interpreting data for identifying performance problems and suggesting solutions.

\section{Objective}

The objective of this study is to share the practical experiences in conducting training needs analysis and to answer the following questions:

- How does the training institution conduct the training needs analysis?

- What are the problems the training needs analyst encounters while conducting the training needs analysis?

\section{Methodology}

This article is primarily based on the practical experiences and knowledge I gained throughout my professional career. However, to verify with my practical experiences with the literatures, some literatures and theoretical perspectives have been reviewed and linked. More importantly, as a TVET practitioner, I have also reflected my own practical experiences, challenges and lessons learnt while conducting rapid market appraisal in writing this article.

\section{My Reflection on RMA}

In 2002, when I was involving as a Master Trainer in Technical Institute for Technical Instruction (TITI), I was assigned to conduct Training Needs Assessment in Acham and Dhading district of Nepal for the Skill for Employment Project funded by Asian Development Bank. I stayed there for more than a month with my colleague. During my stay, I conducted field survey to identify the need of the communities and businesses/industries. Based on my survey, I developed a brief report including major findings and recommendations for the project. In the report, I explained about the occupations that are essential in these two districts for human resource development. But I practically found it very difficult to construct concise suggestions on which occupations or trades, the training centres need to sketch out the training programme to organize so as to fulfil the requirements of the local communities and employers.
Due to various reasons like rapid change in economic activities, social considerations, public movements and the preference of the target group, I found the requirements of the user agencies and the graduates of the training do not match with each other. In addition, I have been told by the TVET providers, donors and number of technical training providers that they also have been facing similar problems and challenges.

In 2005, F-SKILL, a service provider in technical vocational education and training (TVET) in Nepal, contracted me to develop a training programme on training needs assessment for their technical training providers and asked me to address the above mentioned problems. Because of my long term involvement in training needs assessment and curriculum design in the sector of technical education and vocational training, I knew that when it came to training needs assessment, there should not be a long way to conduct the survey. I knew then that I had to virtually reinvent the training needs assessment process and devise a newer, more direct method of collecting data about the needs of the communities and the user agencies. And I needed to adapt the process quickly if I was going to use it in this new business and industry environment. I needed a leaner, swifter, more straightforward methodology that would give me enough information to start building worthwhile identification of the needs of the user agencies. I needed some way to perform the analysis that was relatively of less hassle, quick, flexible, and simple, that added something significant to the educational planning process. After a month of the reviewing the books, articles, journals and surfing relevant websites, I sketched the outlines of the training programme on needs analysis and submitted to F-SKILL. F-SKILL reviewed these outlines for the training programme on Training Needs Assessment and named it as "Rapid Market Appraisal".

Understanding Rapid Market Appraisal In my understanding, Rapid Market Appraisal (RMA) is one of the tools in determining the needs or demand 
of human resources for the business and industry. Basically it is used to undertake a comprehensive study of an employment status in the specific occupational area particularly at a local level. RMA, as opposed to a formal sub-sector analysis, provides a quick, flexible, and effective way of collecting, processing, and analyzing information and data about labour markets (HELVETAS Swiss Intercooperation Nepal, 2015).

Practices of RMA - Theoretical Perspectives During the preparation of the RMA training design, I reviewed a large numbers of books, articles and journals and found that RMA process was the outcome of a Micro and Small Enterprise development effort in Africa in 1960 (Rapid Market Appraisal-Captiva, Africa LLC, Nairobi, Kenya).

In addition, I also got information that this concept was applied as a movement to meet the growing demand of labour in under-developing countries of Africa especially in Kenya, Uganda, and Tanzania. Later on, this process was introduced in agricultural development programmes in Vietnam and Laos in determining the agricultural products (Helvetas Swiss Intercooperation, 2002).

I completed my assignment of designing RMA training for F-SKILL in July 2005. I was assigned to conduct the RMA training with 17 participants from technical training providers of F-SKILL. Thus, in Nepal, F-SKILL introduced RMA process in 2005 for assessing the needs of skilled human resources within the country.

With the success stories of the F-SKILL's Modality of assessing needs of the technical human resources, the Employment Fund Secretariat/ Helvetas Swiss Intercooperation Nepal (EF) replicated this process in 2008 in assessing needs of the technical human resources for training. EF assigned me to design and develop “A Handbook on Rapid Market Appraisal for Practitioners" in 2010. A separate topic on Area Potential Survey (APS) was conducted by my colleague Mr. Chandra Kanta Adhikari, then employee of Helvetas and was incorporated in the Handbook.

At present, this process has been applying by a number of technical and vocational training providers in Nepal while assessing the needs of the training programmes.

\section{What do I get from RMA?}

The development of this process grew out of a frustration with lengthy, costly and intensive formal market survey that I experienced in recent years. I have learned to view the process as collecting information to provide assurance that technical training institutions deliver most appropriate, highquality and employment oriented training for the jobs. RMA provides the following major information:

- Number of skilled workers available at present in specific occupation in predetermined area

- Number of skilled workers needed in specific occupation in predetermined area

- Additional skills of the workers as preferred by employers

- Present occupational interests of local youths

- Existing technical training providers available in the local area

\section{Where do I get information from?}

Much of such data derives from the target population of the study area. However, there are other reliable sources of data that should not be overlooked. The data collector should make sure to interview some of the data sources on the lists below. In this connection, I want to borrow the definition of data sources mentioned in TITI Skill Card, 2005: "Determine Needs Assessment Purpose" which is also valid for RMA that states- "Persons including those in the target population, who may have valuable opinions, facts, or feelings regarding the study, or who may influence any outcome of the study".

\section{Firsthand information}

With my experiences, in business and industry setting, the target population may be employers, employees, district chambers of commerce, employers' 
associations, employees' associations, professional associations, etc (Sharma, 2005, pp. 1-13). Access to job in accordance with knowledge and skills will be facilitated through creation and expansion of information centres, and analysis of the enlisted human resources will be carried out to strengthen effective employment exchange system (National Planning Commission, 2010, pp.65-66).

\section{Clients - Employers}

Employers are probably the most accurate sources of information in determining the needs or demand of business and industry (Finch \& Crunkilton, 1993). Since RMA is a kind of employer survey, I remember Robert Chambers's famous view "Farmer First" and here, "Client First" considers employers as the major source of information for the study.

During the survey, I allow potential employers to tell me the following information about their workers. I use semi-structured interview guide to obtain these information.

- Existing numbers of workers working at present

- Required numbers of workers needed at present

- Required numbers of workers needed for coming years

- Major competencies needed for the organization

- Present salary of the workers

- Types of workers (gender, caste, age and ethnic groups)

\section{Employer Associations - Clients}

Employer associations can provide the most current status of supply and demand situation of the workers of the selected study areas. They can help you to identify the employers and employees for the interviews. The following information could be obtained from them:

- Overall numbers of workers working at present in the industry at local level

- Tentative required numbers of workers in the industry at local level

- Most appropriate group in terms of age, sex, ethic group for the particular occupation

- Preference of the local youth

Employee Associations - The job seekers
I found that employee associations are a good point to start the RMA study. They can also provide current information about the supply-demand situation of the workers in the particular area. They especially help for the acceptance and recruiting the trained people. You get the following information from them:

- Overall numbers of workers working at present in the industry at local level

- Most appropriate group in terms of age, sex, ethic group for the particular occupation

- Preference of the workers

- Sources of workers

Technical Training Providers - The suppliers There might be the numbers of technical training providers already existing in the areas which are providing similar training programmes. They are reliable sources to obtain information about training contents, training demand and other related information.

- Numbers of existing technical training providers

- Trend of training demand

- Interest/attitude of youths by caste, gender and age

- Place the youth prefer to work

- Wage/Salary/Piece work/Job order basis

- Types of work (self/wage) youth prefers to work

\section{Local Youths - The job seekers}

Another important source of data can be local youths who play a major role in making the training programme successful. Taking the interest and preference of the youth into account can help engage the youth in the training course and increase their labour market information.

\section{What other documents do I need to review the before planning the RMA?}

Apart from the reports and documents related to the requirement of skilled human resources at local level, I also review the following sources for planning my RMA study. 


\section{Occupational Dictionaries}

Occupational dictionaries are a good source for identifying the tentative list of duties for an occupation. They help in determining the outlook of the occupation and identifying possible job titles. Some of the more common occupational dictionaries I use when I conduct RMA are:

- Australian Standard of Classification of Occupations (ASCO) (Produced by Australian Bureau of Statistics, Canberra 1996): Australian Standard Classification of Occupations (ASCO) is a skill-based classification of occupations developed as the national standard for organising occupation-related information for purposes such as policy development and review, human resource management, and labour market and social research. The classification includes all jobs in the Australian workforce.

- International Standards of Classification of Occupations (ISCO) (Published by ILO): ISCO is a four-level classification of occupation groups managed by the International Labour Organization (ILO). Its structure follows a grouping by education level. The two latest versions of ISCO are ISCO-88 (dating from 1988) and ISCO-08 (dating from 2008).

- V-TECS Career Cluster Frameworks (July, 2000, U.S. Department of Education, Office of Vocational Technical Education, Career Cluster Brochure).

- Nepalese Standard Occupations Classification (NSOC) (Published by Central Bureau of Statistical Department: Thapathali: Government of Nepal, 2000)

\section{Internet Resources}

The internet has made it possible to access a vast amount of information in an amazingly short period of time. Identifying the right sites on the internet may not be as easy as it looks. Recent job analyses from the occupation(s) under study are a great help in providing a clearer picture of that occupation. There are various sites on the internet where we can find job analyses or profiles. One of the good sites is: $\mathrm{O} * \mathrm{NET}$.
What tools do I need to use for data collection? Since RMA is a small scale study, I always go for using simple and easy tools for collecting quantitative as well as qualitative market information. I therefore use the following tools in collecting data in RMA process.

\section{Semi- structured interview guide to collect market data}

RMA interview does not use a formal questionnaire for information but use a checklist of questions as a flexible guide. RMA interview guide should be carefully designed to identify problems, causes, and solutions. In my experience, the semi-structured interview allows the data collector to ask follow-up questions to probe more deeply into problems, causes and solutions.

\section{Direct Observation for context analysis}

Observation involves watching carefully that takes place and making brief notes in the RMA process. Direct observation is a good way to cross-check respondents' answers. With an RMA observation form, I advise the RMA assessor to examine general items to be observed as: work environment, tools and equipment used, communication process in the workplace, workers' traits, process of performing the skills, manual and so on.

\section{Focus Group Discussion for verification and collection of qualitative data}

Another important tool I use for collecting data in rapid market appraisal is from focus group discussion. It is useful for exploring ideas and obtaining in-depth information about how people think about an issue. I normally conduct focus group discussion to obtain qualitative data such as opinions, experiences, views, feelings and ideas from a small targeted group of people.

\section{How do I plan RMA?}

I recently read a quotation by Einstein who said that if a man was given 60 minutes to solve a problem, he would spend 55 minutes making clear about the problem, and five minutes in solving the problem 
((TITI Skill Card, 2005: Determine Needs Assessment Purpose). Thus, firstly is it necessary to be clear about what is to be accomplished. Before conducting RMA study, it is essential to prepare a plan which answers the following questions:

- What do we need to do?

- What do we expect to achieve?

- Where do we collect information from?

- Whom do we need to meet?

- When do we need to complete your study?

However, I suggest the RMA assessors to follow the following procedures:

\section{i. Define the problem:}

Here, I quote the Chinese proverb "If there is no problem, there is no need to do the things" The problem triggers the need to conduct RMA. Thus, the problem should be defined in specific terms presenting facts of existing situation of the problem with desired situation of the problem in realistic terms in the plan. Normally, I find the following common pitfalls which should be avoided:

- The RMA statement should not address more than one problem.

- The RMA statement should not assign a cause.

- The RMA statement should not make accusations to any organization.

- The RMA statement should not offer a solution.

\section{ii. Identify location}

The next procedure I follow in the planning of RMA is to define the location. The location will give the assessors to indicate the size or extensiveness of the study. The market location may be small as the need of one specific occupation or one industry or one community or a town to the needs of entire nation.

\section{iii. Describe the size}

After identifying the location of the study, then I go for describing the size of the problem in measurable terms. The size of the problem should illustrate the rationale or important of the problem. It tells how the problem is important to solve.

\section{iv. Define the duration}

Duration provides the timeframe of the RMA study. This timeframe should include the time for initial planning, actual field survey, write-up to delivering the final report and making any required presentations. This will give you when should the study be completed?

\section{RMA needs coaching process}

In my experiences, the RMA needs a coaching process for the certain period of time. Single inputs during training/workshop may not be sufficient for the effective implementation of RMA process in real settings. Repeated inputs from experienced RMA practitioners or consultants are required in order to make assessors more confident in the process. Practical training and formal coaching are both essential in the RMA process.

\section{Conclusion}

Job markets are constantly evolving and changing, and therefore market appraisal need to be conducted on a fairly regular basis. An RMA provides a quick and an effective way of obtaining relevant information about the job market system for specific occupational sectors whist at the same time, minimizing cost, delays and working time. It allows to quickly measuring the demand and opportunities for a specific occupation in business and industry as well as geographical locations or for new settings. Finally RMA ensures that the new job seekers receive appropriate, marketable, high-quality training for the job.

\section{References}

Finch, C. R., \& Crunkilton, J. R. (1999). Curriculum development in vocational and technical education. planning, content, and implementation. Allyn and Bacon, 160 Gould Street, Needham Heights, MA 02494.

Glass, K. T. (2015). Complex Text Decoded: How 
to Design Lessons and Use Strategies That Target Authentic Texts. ASCD.

Hartley, D. E. (1999). Job analysis at the speed of reality. Human Resource Development.

Helvetas (2002). Clients First! A Rapid Market Appraisal Tool Kit Theoretical background and experiences from various RMA events. Zurich: Author. Retrieved from http://www.cash learning.org/downloads/a-rapid-market-appraisal toolkit.pdf

HELVETAS Swiss Intercooperation Nepal (2015). Rapid Market Appraisal for the Practitioners Handbook on Rapid Market Appraisal for the Practitioners. Lalitpur: Author. Retrieved from https://www.s4ye.org/agi/pdf/Targeting_And_ Diagnosis/RMA\%20handbook\%20Manual.pdf

HELVETAS Swiss Intercooperation Vietnam (2002) A Guide to Rapid Market Appraisal for Agricultural Product. Retrieved from http://www.crs.org/sites/default/files/tools research/guide-to-rapid-market-appraisal-for agricultural-products.pdf

International Labour Organization (1999). Boosting employment through small enterprises development: The FIT Manual series on Rapid Market Appraisal. Geneva: Author.

Romijn, H. A. (1987). Employment generation through cottage industries in rural Thailand: potentials and constraints.

Sharma, T.N. (2005), Connecting Technical Education and Vocational Training with Employment in Nepal: Current problems, issues and trends; Development. Journal on Technical Education and Vocational Training, 1(9), 1-13

Shrestha, R \& Adhikari, C. K. (2015). A Handbook on Rapid Market Appraisal for the Practitioners. Employment Fund Secretariat: Contributed
Theis, J., \& Grady, H. M. (1991). Participatory rapid appraisal for community development. A training manual based on experiences in the Middle East and North Africa.

TITI. (2005). Determine Needs Assessment Purpose (TITI Skill Card). Bhaktpur: Author.

Tiwari, I. P. (1998). Employment Creation and Income Generation in Rural Regions: Peoples, Places, Activities and Interventions in Nepal. Center for Rural and Urban Studies and Transfiguration.

Note: The author is a practitioner in TVET training design and development. 